\title{
Determination of Hurricane-Induced Barge Impact Loads on Floodwalls using Dynamic Finite Element Analysis
}

By:

Daniel J. Getter ${ }^{1}$, Michael T. Davidson ${ }^{1}$, Gary R. Consolazio ${ }^{*}$, and Robert C. Patev ${ }^{2}$

${ }^{1}$ Department of Civil and Coastal Engineering, Engineering School of Sustainable Infrastructure \& Environment, University of Florida, P.O. 116580, Gainesville, FL 32611, USA

* Corresponding author: E-mail: GRC@CE . UFL . EDU, Tel. +1 (352) 392-9537 ext. 1510

2 Risk Management Center, US Army Corps of Engineers, 696 Virginia Road, Concord, MA 01742, USA

\begin{abstract}
During hurricane events, moored barges are at risk of being propelled by high winds and impacting flood protection walls in the vicinity. Cities like New Orleans, Louisiana are at particular risk for such hazards, due to the preponderance of canals and moored barges throughout the city combined with high hurricane risk. Unfortunately, limited information is available to estimate the magnitude of barge impact loads for the design of floodwalls. In this paper, forces associated with hurricane-wind-propelled barge impacts on floodwalls are quantified using high-resolution dynamic finite element simulations. Such simulations account for highly nonlinear material deformation in the impacting barge, nonlinear soil response, and dynamic interaction between the barge, wall, and soil. The paper presents force histories for a variety of representative impact scenarios which can be used directly in dynamic analysis of floodwalls. Additional guidance is provided for employing the force results in static design scenarios.
\end{abstract}

\section{Keywords}

barge; hurricane; flood wall; finite element impact simulation; impact loads 


\section{Highlights}

- During a hurricane, barges may break loose from their moorings; be propelled by wind; and eventually impact protective floodwall structures

- A high-resolution, fully-detailed, materially-nonlinear finite element model of a jumbo hopper barge is developed

- Simulations of barge impacts on floodwall structures with pile foundations are performed

- As impact-momentum increases, a plateau of impact force is eventually reached

- Oblique-angle impacts produce smaller forces than side impacts, however side impacts are statistically less likely to occur

\section{Introduction}

The city of New Orleans, Louisiana, USA is located near the mouth of the Mississippi River on the coast of the Gulf of Mexico, and large portions of the city have been constructed at or below sea level. Consequently, New Orleans is at significant risk of water intrusion resulting from both seasonal river flooding and hurricane-induced storm surges. Thus, the city and many surrounding areas are protected with an extensive system of earthen levees and concrete floodwalls that are designed and maintained by the U.S. Army Corps of Engineers (USACE). During hurricanes, these floodwalls are subjected to loads from elevated storm surges, waves, wind, and wind-propelled debris. After Hurricane Katrina directly struck New Orleans in 2005, it was observed that numerous river barges, which had been moored throughout the city waterways, broke loose from their moorings and were propelled through the channels by hurricane winds. Thus, floodwalls throughout New Orleans-and any region where this scenario can occur-are at risk of being damaged by impact from aberrant, windpropelled barges (Fig. 1). 

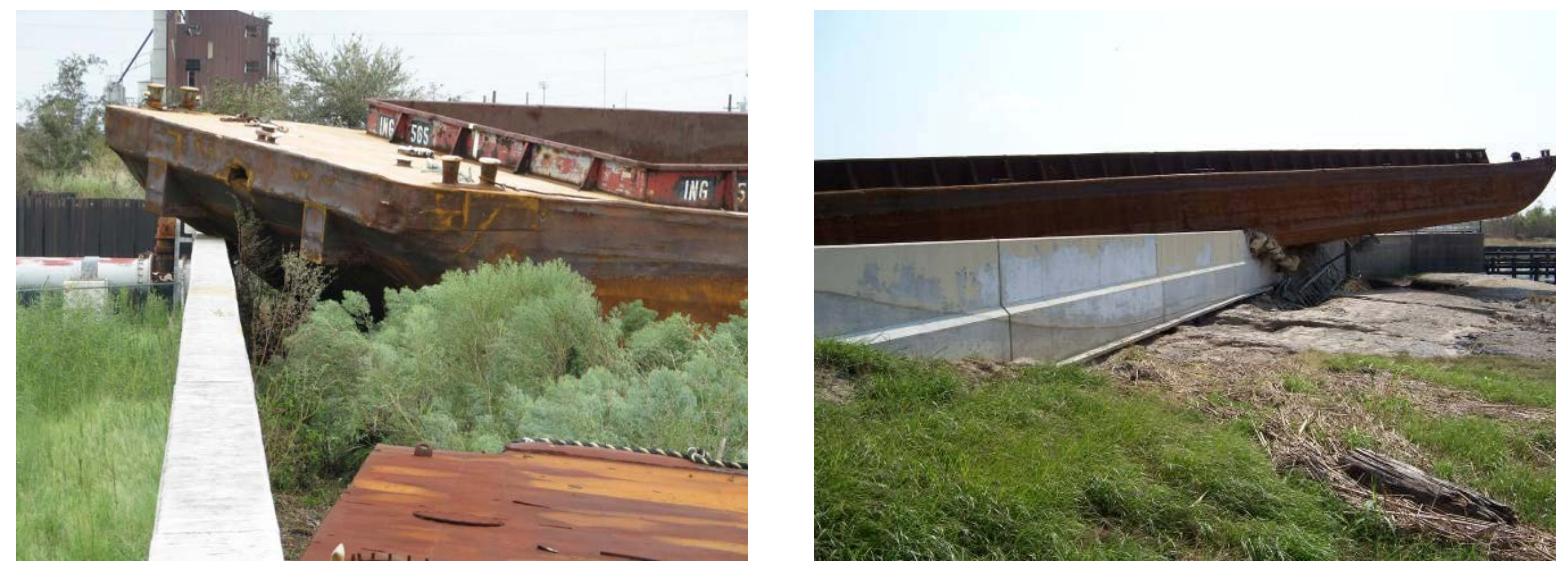

Fig. 1. Aberrant barges that impacted New Orleans area floodwalls during Hurricane Katrina. (Source: U.S. Army Corps of Engineers)

Given the severe consequences associated with the barge impact hazard, the goal of the current study was to quantify barge impact loads on typical floodwalls using highresolution dynamic finite element analysis. Loads quantified by this study can be used to design new floodwalls or to assess the need for protecting or replacing existing infrastructure in flood-prone areas.

\section{Background}

Following a number of structural failures resulting from barge and ship collisions, significant research effort has been devoted to quantifying loads associated with barge impact with various waterway structures. For bridges, design codes in the U.S. [1] and Europe [2] prescribe barge impact loads and related design requirements. Ongoing research work is being carried out to further refine the U.S. code procedures by developing more accurate predictions of impact loads [3,4,5] and improved analysis procedures [6,7]. However, these procedures are not readily adapted to analyzing floodwalls subjected to wind-driven barge impact, primarily because they were derived assuming that head-on impact will occur between the barge bow (front portion) and bridge pier. In contrast, during a hurricane, an unrestrained wind-driven barge could impact a floodwall at any angle, permitting impact by the bow, stern (rear portion), or side of the barge. 
Research focused on barge impact forces on other waterway structures has been conducted by the USACE. Specifically, studies were previously undertaken to quantify barge impact loads on semi-rigid walls—-such as those surrounding locks—by means of a series of full-scale barge flotilla impact experiments [8,9]. The two USACE studies culminated in design provisions and load prediction equations, referred to as ETL 1110-02-563 [10], which pertain to barges colliding with lock wall structures. However, impact loads predicted using the USACE ETL equations could be overly conservative when applied to barge impacts with floodwalls, because floodwalls are much more flexible than the relatively rigid wall structures considered in the ETL provisions [10]. Furthermore, like the bridge design procedures described above, impacts from the barge stern or barge side are not considered in the ETL provisions. Given the limitations of applying existing analysis methods to the problem of hurricane wind-driven barge impacts on floodwalls, the current study was undertaken to quantify impact loads for a variety of feasible impact conditions using finite element impact simulations.

\section{Finite element model features}

In order to perform contact-impact analyses of barge collisions, finite element (FE) models of a typical jumbo hopper barge, and two USACE floodwalls were developed for analysis using the LS-DYNA code [11]. All finite element models were developed based on detailed structural drawings that were provided to the authors by a barge manufacturer.

\subsection{Jumbo hopper barge}

The most common type of barge traversing U.S. waterways—including those surrounding New Orleans - is the jumbo hopper barge. Thus, throughout this study, a jumbo hopper barge measuring $59.4 \mathrm{~m}$ (195 ft) long and $10.7 \mathrm{~m}$ (35 ft) wide was used for all impact simulations. 


\subsubsection{Structural modeling}

As illustrated in Fig. 2a, the jumbo hopper barge is divided into three zones along its length: bow, hopper, and stern. Watertight bulkheads, spaced at $12.3 \mathrm{~m}$ (40.5 ft) intervals along the hopper region, act to compartmentalize the barge. The entire barge structure was modeled using more than 900,000 nonlinear quadrilateral shell elements, in which elements are generally $7.5 \mathrm{~cm}$ (3 in.) square (Figs. 2b-c). Note that care was taken to adequately discretize shell elements across the widths of structural member components (e.g., angle legs, channel flanges) so as to enable capturing of local buckling. Specifically, for all structural shapes within the barge, a minimum of three element divisions were modeled across the width of each member leg, flange, and web.

For each of the three barge zones, external surfaces and internal structural members were discretely modeled (Figs. 2-4). Throughout the three barge zones, internal and external plate thicknesses varied between $7.9 \mathrm{~mm}$ (5/16 in.) and $15.8 \mathrm{~mm}$ (5/8 in.), and internal stiffening members consisted primarily of steel channel and single angle members. 

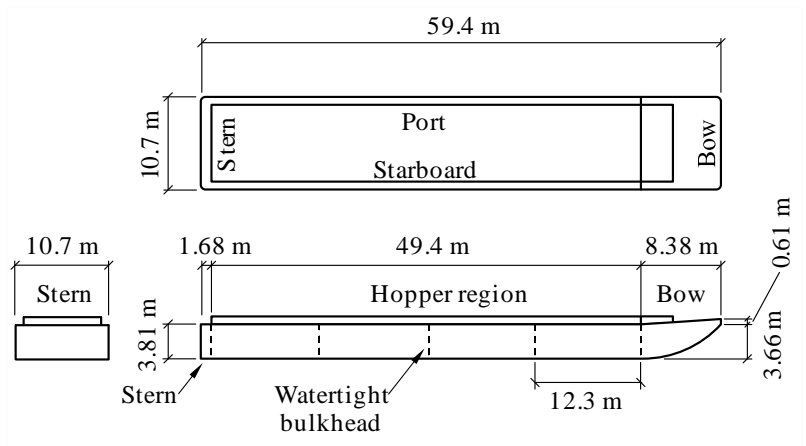

a)

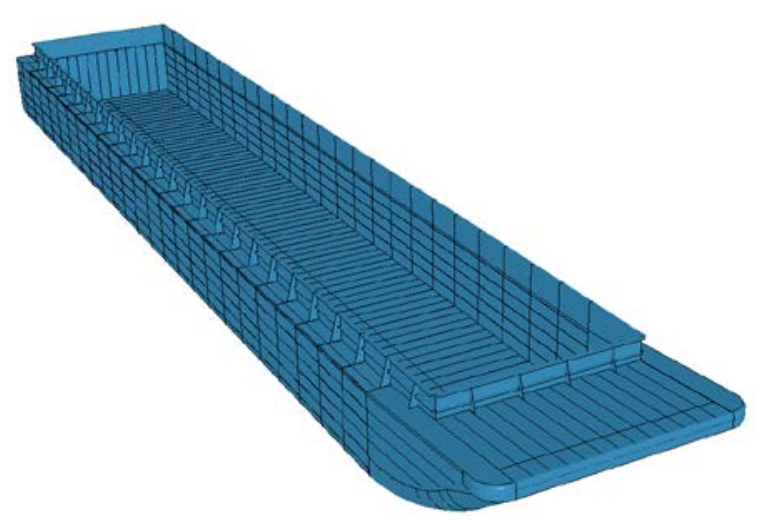

b)

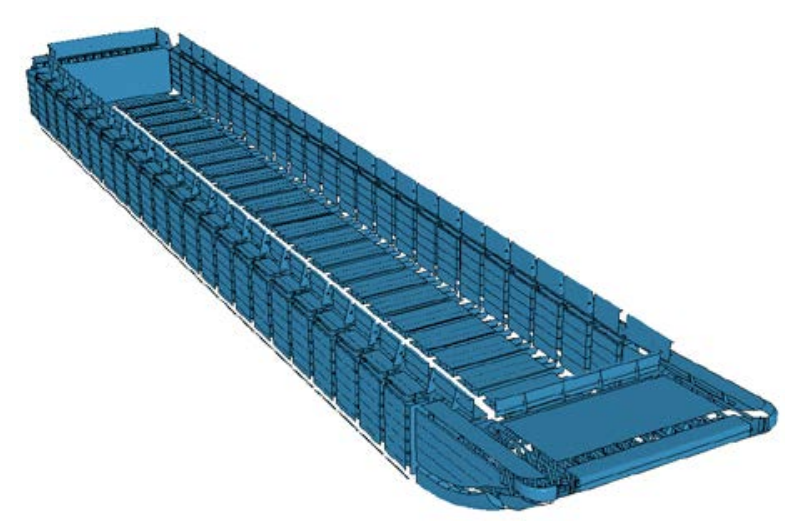

c)

Fig. 2. Jumbo hopper barge FE model (mesh not shown for clarity): a) Schematic plan and elevation view; b) Perspective view; c) Exploded view.

The barge bow zone is composed of fourteen (14) internal rake trusses and frames, transverse bracing members, and several external hull plates of varying thicknesses (Fig. 3a). The hopper zone consists of a barge bottom plate and hopper bottom plate that are connected by closely spaced transverse stiffener plates (Fig. 3c). Additionally, the hopper zone contains 24 port and 24 starboard sidewall units (referred to as sidewall modules). Each sidewall module is stiffened by closely spaced longitudinal plates and angles. These longitudinal members terminate at watertight bulkheads, which bound each group of six modules. The stern zone contains fourteen internal trusses and frames (Fig. 4). Stiffening plates are closely spaced (vertically) at the port and starboard corners of the stern, where both transverse and longitudinal stiffening angles are attached to the corner stiffening plates. 


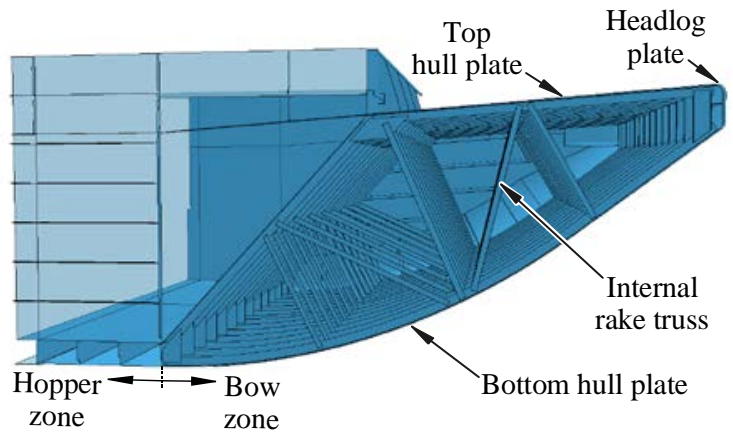

a)

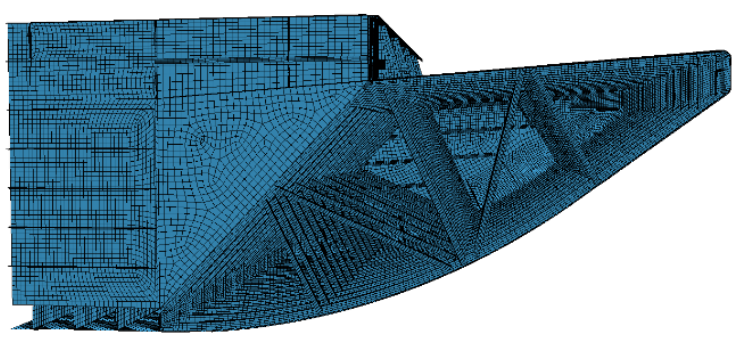

b)

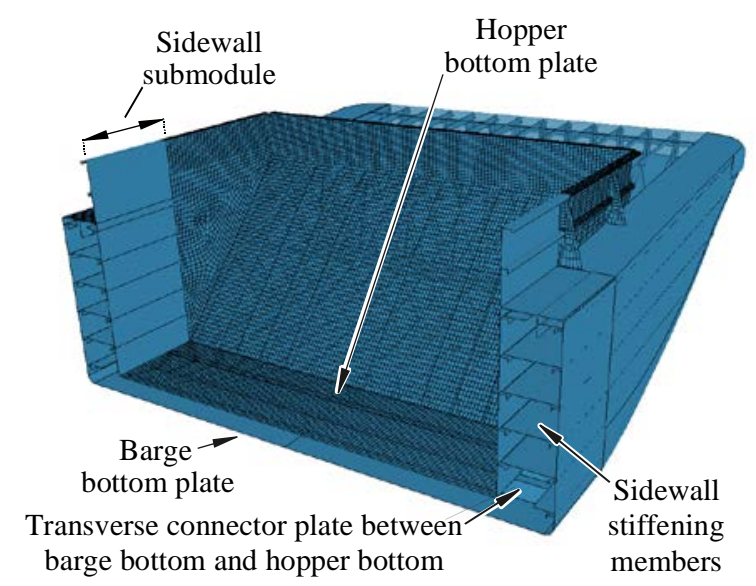

c)

Fig. 3. Barge bow region finite element model details (partial mesh shown for clarity).

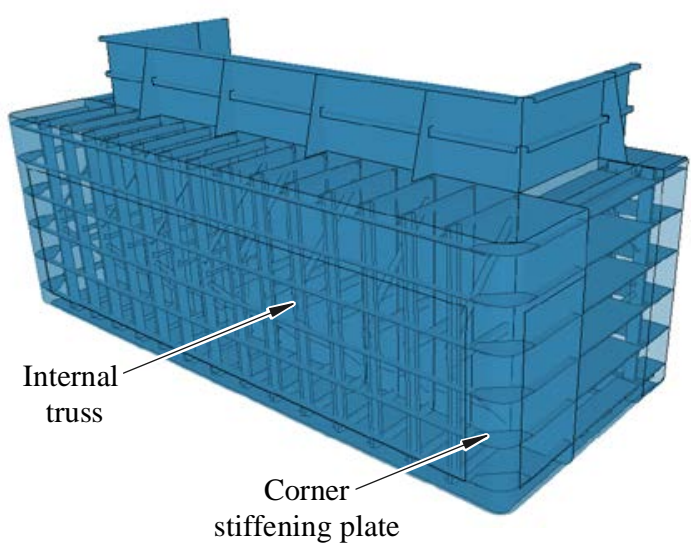

a)

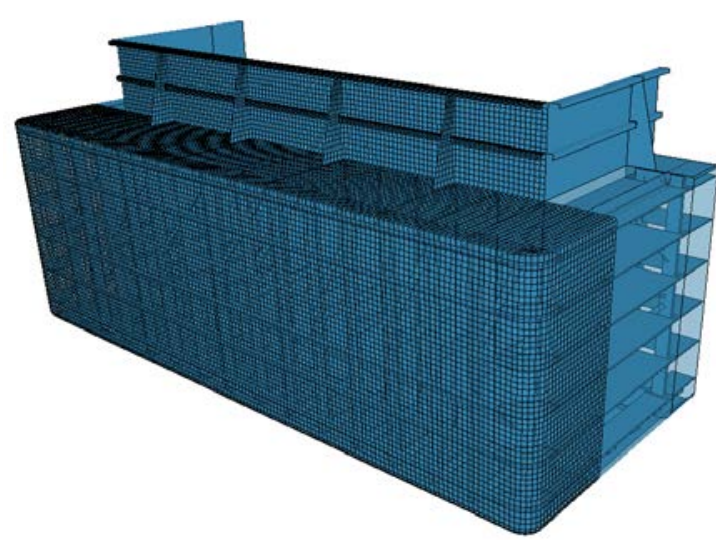

b)

Fig. 4. Barge stern region finite element model details (partial mesh shown for clarity).

\subsubsection{Constitutive modeling and element details}

Most barges fabricated in the U.S. are constructed from A36 structural steel, which has a specified uniaxial tensile yield stress of $250 \mathrm{MPa}$ (36 ksi). In this study, an elastoplastic material model (i.e., constitutive relationship) representing the nonlinear behavior of 
A36 steel is implemented. The constitutive relationship is defined using the MAT_PIECEWISE_LINEAR_PLASTICITY material model in LS-DYNA $[11,12,13]$ and includes both linear elastic and nonlinear plastic components. Determination of whether material behavior is elastic or plastic depends on the outcome of evaluating the Von Mises yield criterion. When the Von Mises stress (effective stress) is less than the uniaxial tensile yield stress, linear elastic behavior is modeled with an elastic modulus of $200 \mathrm{GPa}(29,000 \mathrm{ksi})$ and Poisson's ratio of 0.33 . Otherwise yielding is deemed to have occurred and isotropic plasticity is used to compute incremental effective plastic strains.

Material hardening-i.e., evolution of the Von Mises yield surface-is described using a piecewise linear relationship between effective true stress and effective plastic strain. For the A36 material used in the barge model, the piecewise linear curve shown in Fig. 5 is used to describe hardening [4]. Material failure (rupture) occurs at a strain of 0.2 and at an effective true stress of $480 \mathrm{MPa}(69.8 \mathrm{ksi})$. This material model is assigned to the more than 900,000 four-node, fully integrated shell elements that make up the barge model.

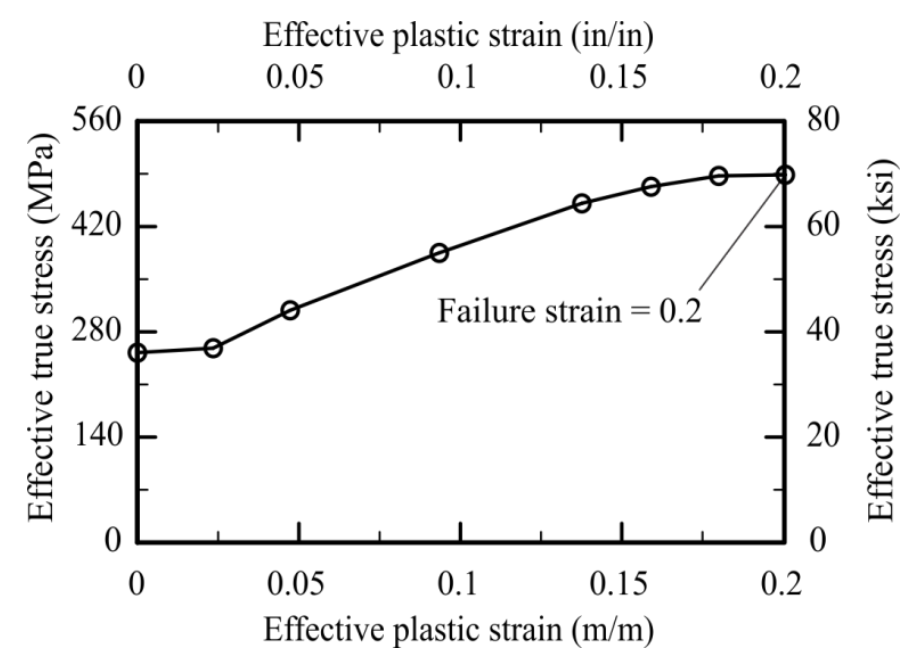

Fig. 5. Barge structural steel material parameters.

The use of shell elements for all barge structural components (i.e., all plates and structural shapes) allowed both plate and member buckling to occur during impact (as appropriate) throughout the barge. Additionally, using shell elements to model internal 
structural members of the barge allowed these components to undergo local material failure (fracture), which in LS-DYNA simulations can be approximated through element deletion. Angle and channel structural shapes were modeled with a sufficient number of elements so that reverse curvature could develop in the event of local member buckling.

Steel components in barges are joined together by welds. In the finite element model, localized welds (spot welds) were modeled by rigid beams that connected two nodes (from different structural members) together. Connection failure was accounted for through element deletion upon failure of the joined shell elements. Spot welds were distributed at a sufficient density to emulate welds present in the physical barge.

\subsubsection{Barge model validation}

The accuracy of the finite element model has been validated in multiple, separate studies dealing with barge-structure impact simulation. In one study, forces measured during full-scale experimental barge impact tests of a rigid concrete wall structure were compared [14] to impact forces computed using the finite element barge model described herein. A similar follow-up study involved making comparisons between experimental and finite element impact force data for a flexible concrete guide wall structure [15]. In both studies $[14,15]$, good agreement was observed between experimental and finite element impact force data. To further validate the accuracy of the bow portion of the barge model at high levels of deformation, a series of controlled (laboratory) pendulum impact experiments were carried out on reduced (40\%) scale barge bows. Comparisons of pendulum impact force data and corresponding finite element simulation data showed good agreement [16]. Consequently, the barge finite element model used herein is considered suitable for use in modeling barge-wall impact events. 


\subsubsection{Barge weight}

Typically during hurricane events, hundreds of unloaded (empty) barges are moored within the New Orleans levy system, while barges containing cargo are anchored outside of the levy system. Accordingly, the current study focused on the hazard posed by unloaded barges which have broken loose from their moorings. According to AASHTO [1], a typical empty jumbo hopper barge has a displacement tonnage (total weight of barge minus cargo) of 181 metric tons (200 short tons). However, barge weights vary by manufacturer. The barge that was modeled for this study has a bare steel weight of 258 metric tons (285 tons). Given the variability of barge weights, and to account for the potential for residual cargo left in the hopper region, a relatively small amount of additional mass was distributed throughout the hopper region in the FE model. With this addition, the full system (barge and residual cargo) weighed 330 metric tons (360 tons) and carried a draft of $61 \mathrm{~cm}(2 \mathrm{ft})$ in the buoyancy system described below. See [17] for additional cargo modeling details.

\subsubsection{Buoyancy modeling}

The buoyant effect of water surrounding the barge was modeled by means of distributed springs connected to the bottom surface of the barge. Specifically, a set of more than 26,000 discrete springs was attached to barge bottom (outer surface) nodes throughout the bow, hopper, and stern zones (Fig. 6a). These springs were anchored at nodes located $305 \mathrm{~m}$ (1000 ft) above the corresponding barge bottom nodes, and these top nodes were restrained from translation (Fig. 6b). Because the barge underwent significant horizontal motion during collision simulations, a large (305 m, $1000 \mathrm{ft}$ ) vertical spring offset distance was used to maintain approximately vertical spring orientations, which in turn, ensured the integrity of the buoyancy forces acting on the barge. 


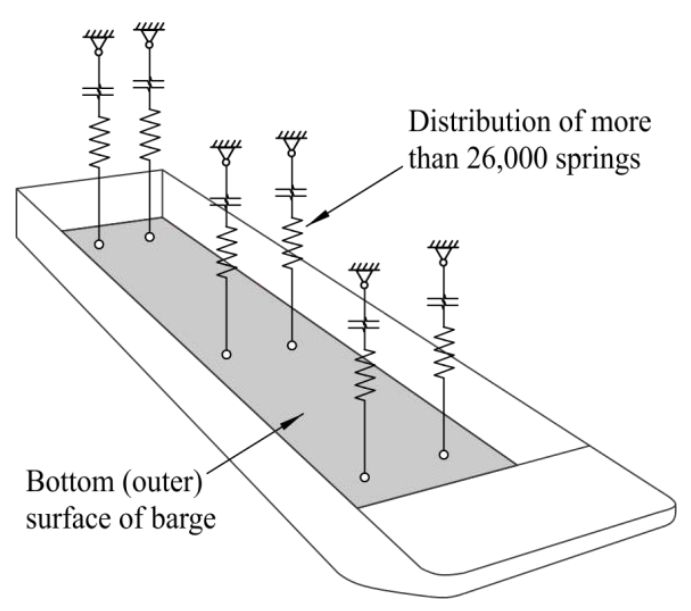

a)

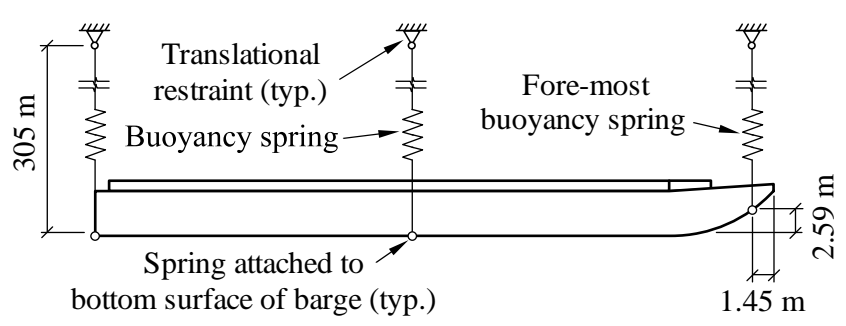

b)

Fig. 6. Buoyancy spring system: a) conceptual schematic; b) elevation schematic (with dimensions).

The bottom surface of the barge in the hopper and stern zones, which were fitted with buoyancy springs, remained submerged (i.e., remained below the waterline in the model space) throughout collision simulations. However, this was not the case for portions of the bow zone. To ensure that nodal buoyancy forces were only generated during times at which the nodes were submerged, gaps were incorporated into the force-deformation definitions for springs that were attached to nodes in the bow zone.

Buoyancy springs were defined as nonlinear elastic (tension-only) elements. The stiffness of a given buoyancy spring was determined by calculating the tributary barge surface area supported by the spring and multiplying this value by the density of water. These stiffness values were small, ranging from 175 - 700 N/m (0.001 - 0.004 kip/in.), which avoided developing unrealistically concentrated buoyant forces acting on the barge hull. Stiffness values for each spring varied in proportion to the (element mesh based) surface area of barge that it supported.

\subsubsection{Contact modeling and computational efficiency}

For all collision simulations conducted in this study, barge collision forces were quantified using contact-impact algorithms in LS-DYNA [11]. Forces developed between the 
barge and floodwall were developed based on interaction between any of a set of specified nodes on the barge model and any of a set of specified element faces (shell or solid) on the impacted structure. As an illustration of how the contact definition was implemented for a given case, consider the barge (nodal) contact definition shown in Fig. 7. In this case, computational efficiency was achieved by only specifying those nodes on the barge that could potentially come into contact with the wall structure during collision. An additional contact definition was employed which monitored self-contact between specified internal and external barge components.

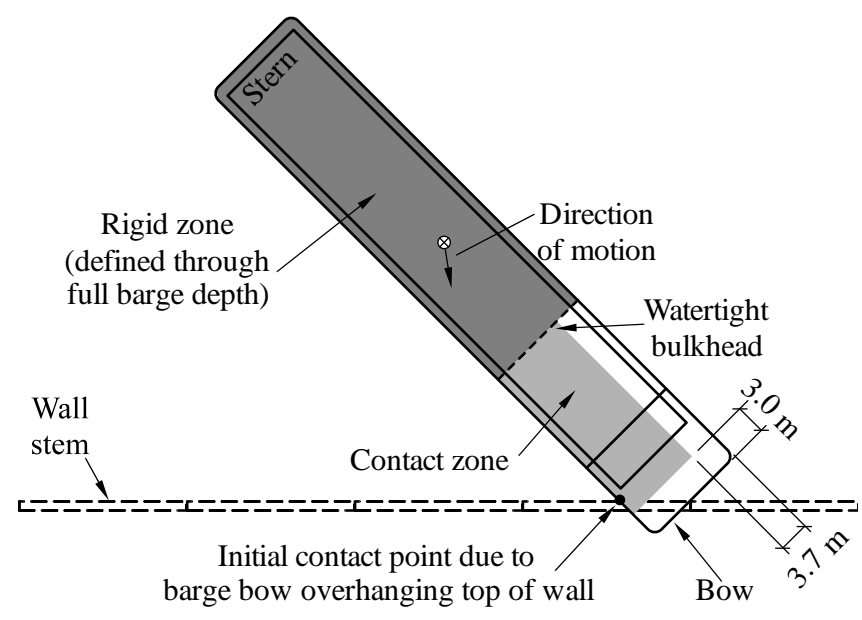

a)

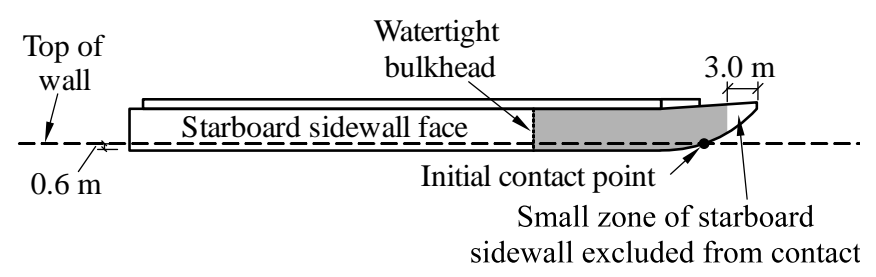

b)

Fig. 7. Representative barge model contact and rigid zones: a) Plan view; b) Elevation view.

In the demonstration impact analysis case (Fig. 7), only nominal stresses were developed in portions of the barge where neither barge-to-structure contact nor self-contact (internal contact) were applicable. Consequently, to improve computational efficiency, these portions of the barge were assigned a rigid material model that substantially reduced the analysis time. For each impact condition simulated (bow impact, stern impact, side impact), 
analogous schemes (similar to those shown in Fig. 7) were used to efficiently incorporate barge-wall contact, barge self-contact, and rigid element zones into the FE barge model.

\subsection{Hurricane protection walls}

Two different hurricane floodwall structures were considered in this study:

- USACE Hurricane Protection Office (HPO) wall located near St. Bernard Parish;

- USACE Protection and Restoration Office (PRO) wall located near Algiers Canal.

Both walls are common designs that are in service throughout the New Orleans flood protection system. The HPO and PRO floodwalls are composed of multiple pile-supported structural units (hereafter referred to as “monoliths”), which are connected to one another by a non-structural seal material, to form a continuous wall. Consequently, each FE wall model consisted of a series of identical, structurally independent monolith models.

\subsubsection{HPO wall}

Overall dimensions and features for a single HPO monolith—specifically, the T wall for Hydraulic Reach SB11, near St. Bernard Parish—are shown in Fig. 8a. Each monolith

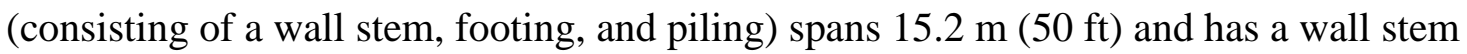
height of $3.4 \mathrm{~m}(11 \mathrm{ft})$. The reinforced concrete (R/C) footing and wall stem are supported on two rows of HP 14x73 piles ( $\mathrm{H}$ piles), where the pile row on the protected side of the wall is staggered. The H-piles are inclined at a 1:2 (horizontal-to-vertical) batter, have a soilembedment length greater than $27 \mathrm{~m}$ (90 ft), and are spaced along the monolith at $1.7 \mathrm{~m}$ (5.6 ft). A line of steel sheet piling is cast into the footing, adjacent to the H-piles on the protected side. Because this piling is provided primarily for seepage control (and not for structural resistance), it was excluded from the structural FE model.

The purpose of this study was to quantify impact loads, not to simulate or assess wall damage or failure. Therefore, to achieve conservative predictions of impact forces, wall stiffness degradation caused by cracking or yielding was not considered. Further, linear 
elastic constitutive models were employed for R/C and steel materials [with elastic moduli of $25 \mathrm{GPa}(3,600 \mathrm{ksi})$ and $200 \mathrm{GPa}(29,000 \mathrm{ksi})$, respectively]. Accordingly, the LS-DYNA MAT_ELASTIC material model $[11,12,13]$ was assigned to all R/C and steel components of the wall. The level of conservatism resulting from this assumption was limited, because wall system resistance was largely controlled by soil stiffness. As described below, a nonlinear treatment of soil resistance was included in the FE model.

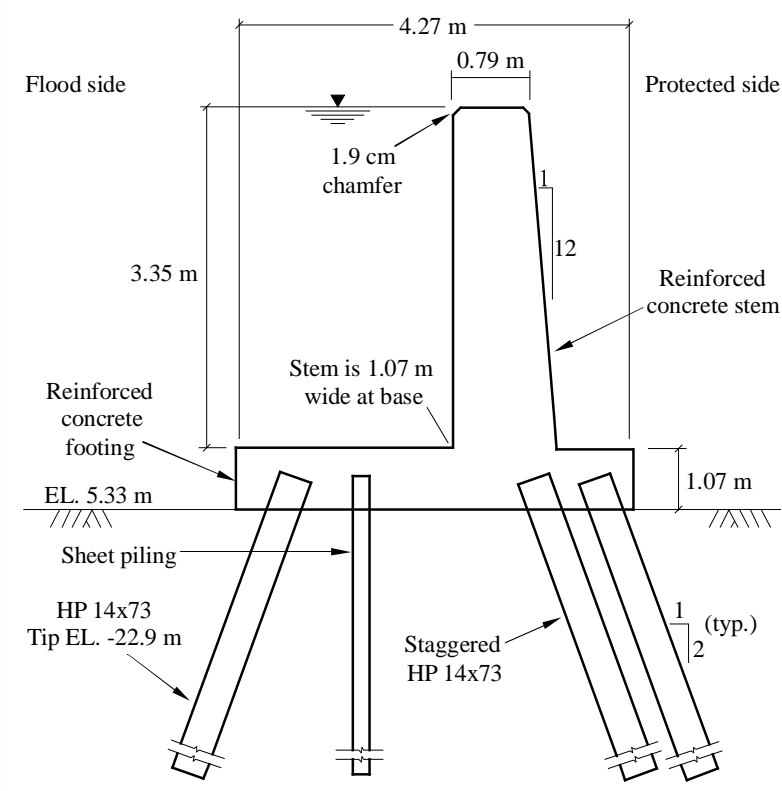

a)

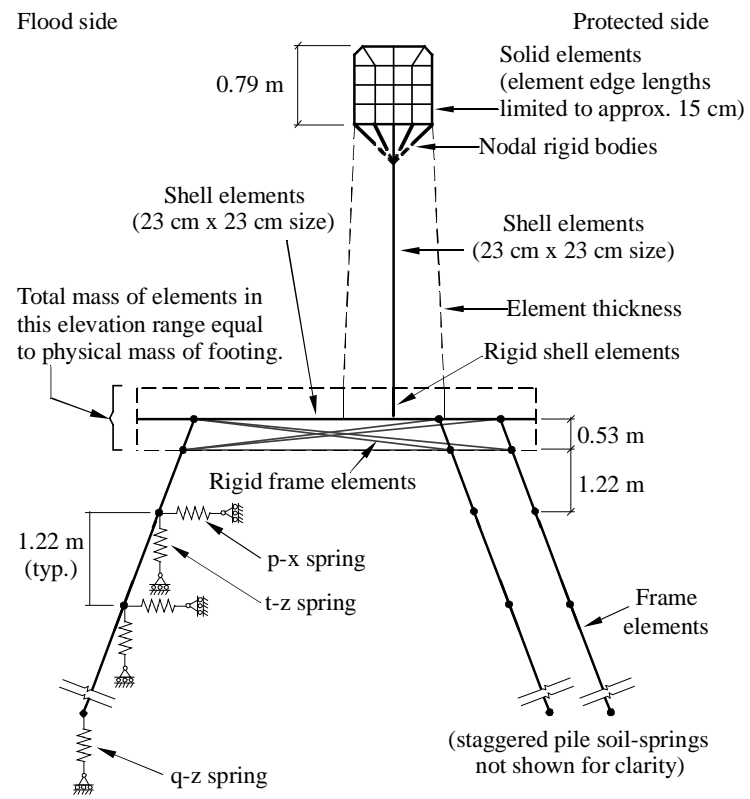

b)

Fig. 8. Schematic of HPO wall monolith: a) Monolith features; b) FE model features.

A schematic diagram of the HPO monolith FE model—consisting of a wall stem, footing, H-piles, and soil-is shown in Fig. 8b. For most of the collision simulations conducted (see Section 4), the barge model initially contacted the top surface of the wall stem. Therefore, linear elastic solid elements were used in this zone to provide a physically representative contact surface between the wall stem and barge. For all solid elements included in the HPO monolith model, the edge length dimensions were limited to approximately $15 \mathrm{~cm}$ (6 in.) (i.e., limited to twice the element edge dimensions defined for 
the shell elements of the barge model). A 1.9-cm (0.75-in.) chamfer was included for the solid elements along the top of the wall stem. Linear elastic shell elements—with physically representative structural and contact thicknesses — were used to model the remainder of the wall stem and the footing. Nodal rigid bodies were used to structurally tie the top portion of the wall stem (consisting of solid elements) to the underlying wall stem shell elements.

The HPO wall R/C footing is $3.5 \mathrm{ft}$ thick, and hence, elements from the overlying wall stem and underlying H-piles that intersect the physical thickness of the footing were given special consideration (Fig. 8b). Specifically, portions of the wall stem shell elements that physically intersect the top half-thickness of the footing shell elements were modeled using a rigid material model. Additionally, H-pile (resultant frame) elements intersecting the bottom half-thickness of the footing shell elements were fitted with rigid (frame element) braces. The footing was modeled in this manner to produce flexible lengths of pile that terminated at the physical bottom elevation of the footing. Finally, the mass of all elements that fell within the footing thickness were calibrated to match the physical footing mass.

While the main focus of this paper is to conservatively characterize maximum barge impact forces on floodwalls, the broader study also includes modeling of soil-structure interaction effects, as documented in [17]. For example, detailed soil layer profiles and soil constitutive curves are given in Ch. 3 of [17]; also, the results of a soil sensitivity study are given in Ch. 4 of [17]. Summarily, soil resistance (soil-structure interaction) was modeled using distributed nonlinear springs connected to every pile node. These springs simulated lateral soil resistance (p-x and p-y) and axial skin friction $(\tau-\mathrm{z})$. A single spring was included at the embedded end of every pile to provide the appropriate tip resistance (q-z). Constitutive (force-displacement) curves for each of these springs were developed using commonlyemployed empirical resistance models that are based on soil strength parameters (e.g., shear modulus, Poisson’s ratio) $[18,19,20]$. Soil parameters were determined using on-site 
geotechnical investigation data. Soil springs were prescribed unique constitutive curves at each elevation to reflect changing soil parameter values throughout the embedment depth.

\subsubsection{PRO wall}

The structural configuration for the PRO monolith considered in this study - the T-wall near Algiers Canal in Plaquemines Parish—is shown in Fig. 9a. The monolith is $8.2 \mathrm{~m}$ (27 ft) in length with a relatively short wall stem height of $1.4 \mathrm{~m}(4.5 \mathrm{ft})$. The PRO wall stem and footing are composed of reinforced concrete and are supported on two rows of prestressed concrete piles spaced at $1.4 \mathrm{~m}$ (4.5 ft). The piles are inclined at 1:2 (horizontal-tovertical) and are embedded more than $15 \mathrm{~m}(50 \mathrm{ft})$ into the soil.

A schematic diagram of the PRO monolith FE model is shown in Fig. 9b. In concept, the schematic is identical to that of the HPO wall; only the specific pile type and member dimensions are different. It was assumed that the piles of the PRO monolith were prestressed primarily to resist pile installation (driving) stresses, and hence, prestressing forces were not included in the PRO structural FE model. Note that, as before, sheet piling was not included in the PRO structural FE model.

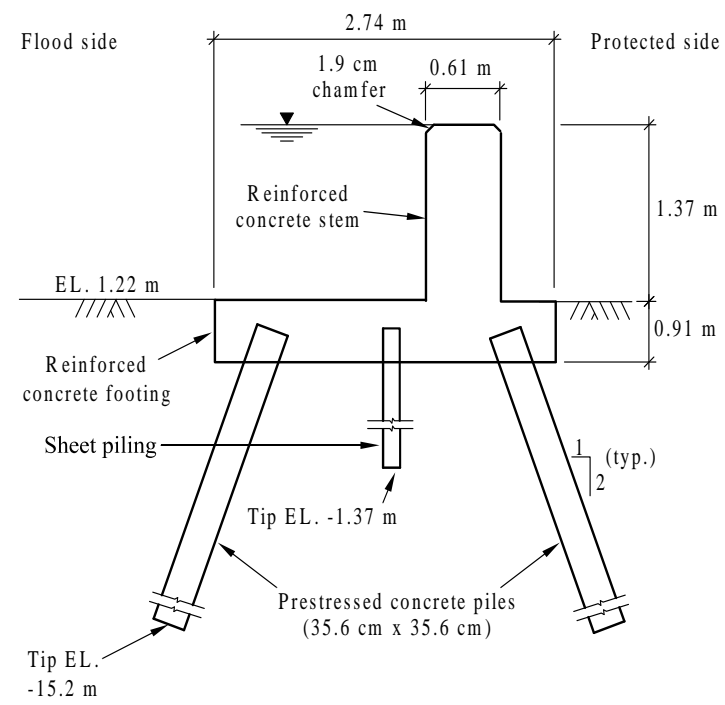

a)

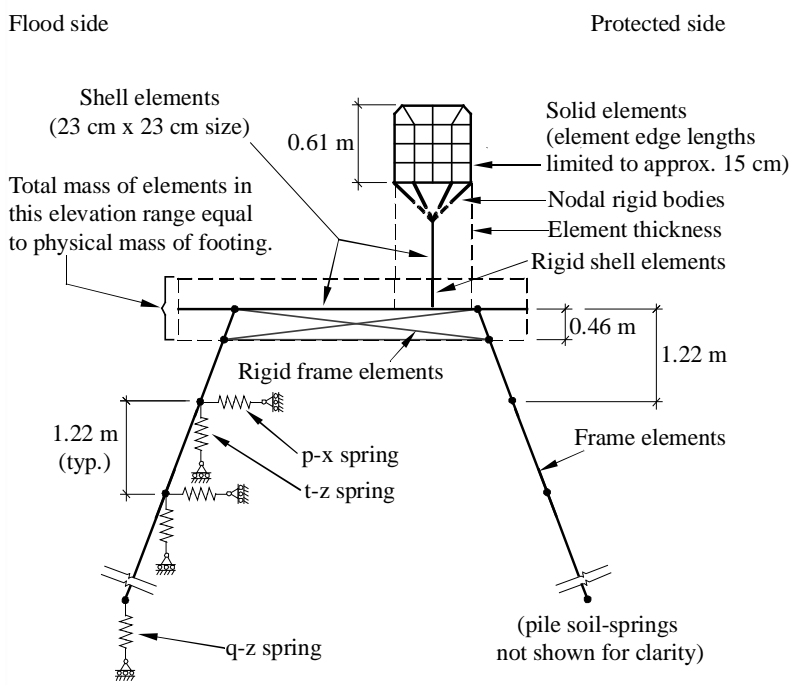

b)

Fig. 9. Schematic of PRO wall monolith: a) Monolith features; b) FE model features. 


\section{Parametric study}

Using high-resolution finite element models of the hopper barge, HPO wall, and PRO wall, more than 40 dynamic impact simulations were conducted. Of the full simulation set, 16 impact simulations (hereafter referred to as "baseline” simulations) served as the primary set from which conclusions were drawn. As illustrated in Fig. 10, the baseline simulation set consisted of empty hopper barge impacts at various angles with respect to the wall. For the baseline simulations, most model parameters were held constant (e.g., barge weight, draft, and initial velocity), and only the impact angle was varied. The eight impact cases shown in Fig. 10 were simulated for both the HPO wall and PRO wall. For the entire baseline simulation set, the initial impact velocity was equal to $2.6 \mathrm{~m} / \mathrm{s}$ (5 knots) normal to the wall ( $\mathrm{V}_{\mathrm{x}}$ in Fig. 10) and $0.51 \mathrm{~m} / \mathrm{s}(1 \mathrm{knot})$ transverse to the wall $\left(\mathrm{V}_{\mathrm{y}}\right)$. (Impact velocities were established, in part, based on results obtained from separate computational fluid dynamics, CFD, simulations of barge-wind-water interactions. For additional details see [23]). Because the unloaded barge carried a draft of only $61 \mathrm{~cm}(2 \mathrm{ft})$, a significant portion of the raked bow protruded over the wall during bow impact scenarios (Fig. 11). Force histories and maximum forces predicted by the baseline simulations are presented in Sections 5.1 and 5.2.

In addition to the 16 baseline impact cases, approximately 30 supplemental simulations were conducted to assess the sensitivity of impact forces to various model parameters such as barge positioning, impact velocity, soil resistance, and pile head fixity. Selected results for these sensitivity analyses are discussed in Section 5.3.

Note that concurrent with dynamic barge impact loading, a variety of static nonimpact loads were also imposed on the wall model, including gravity, hydrostatic pressure, and equivalent-static wave loads. Water loads were provided by the USACE and were consistent with the site-specific load levels that were used to design each wall monolith [17]. 


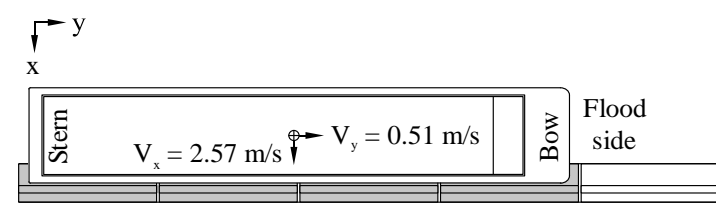

a) Side $0^{\circ}$

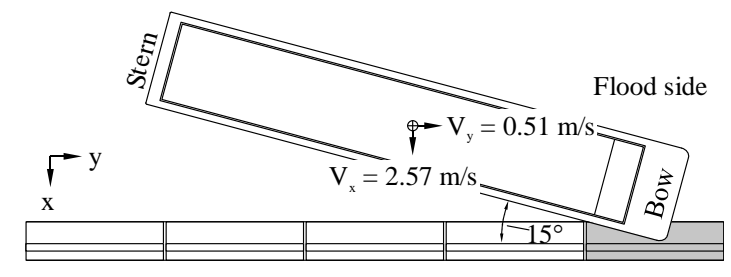

c) Bow $15^{\circ}$

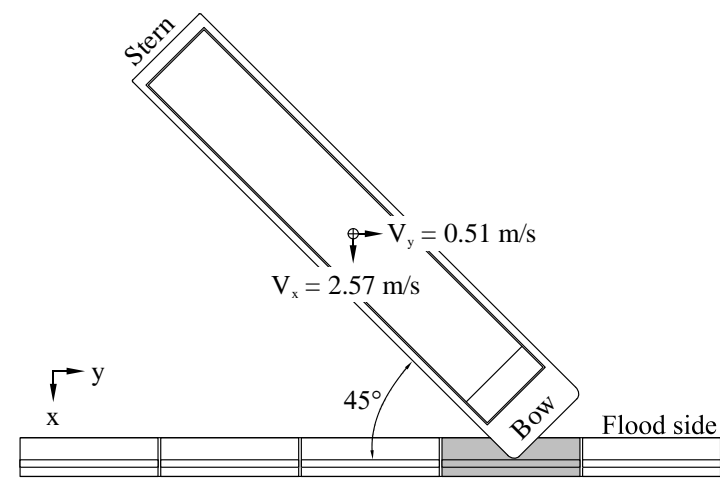

e) Bow $45^{\circ}$

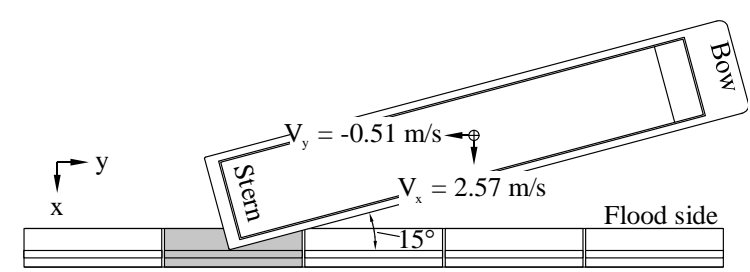

g) Stern $15^{\circ}$

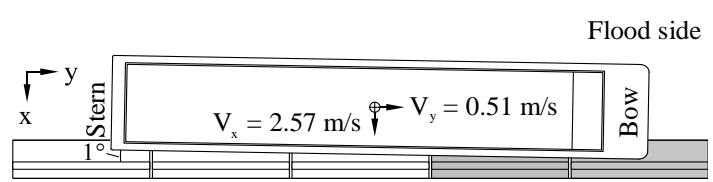

b) Side $1^{\circ}$

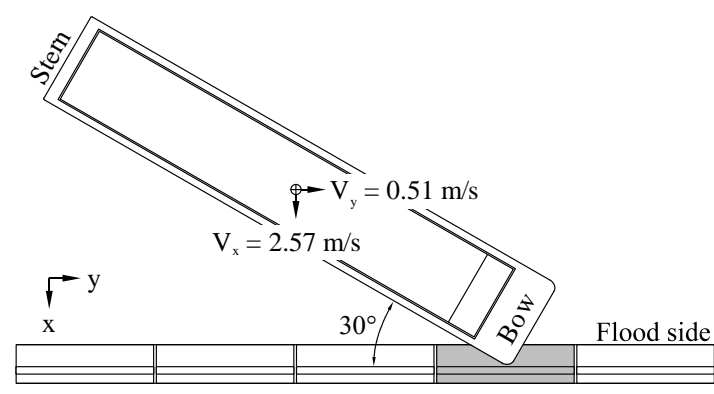

d) Bow $30^{\circ}$

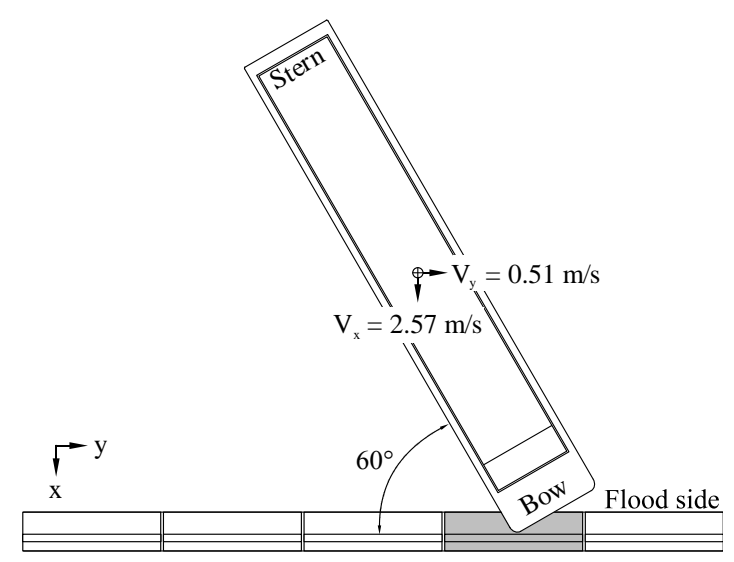

f) Bow $60^{\circ}$

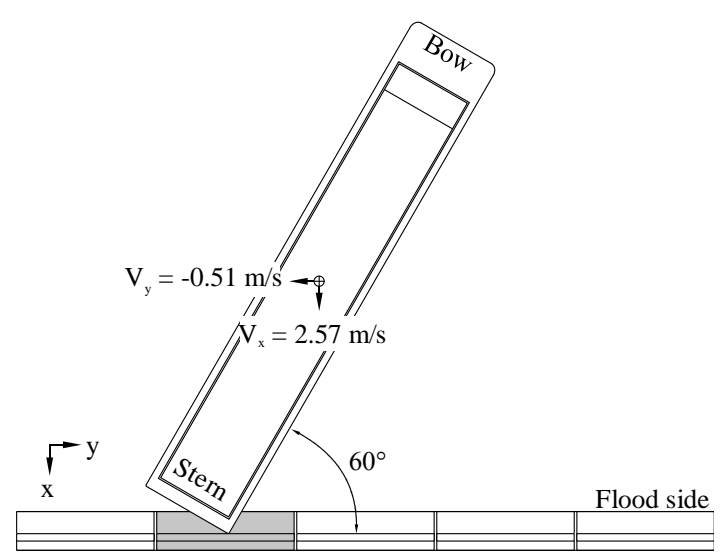

h) Stern $60^{\circ}$

Fig. 10. Impact conditions for baseline simulation set (impacted monolith highlighted in grey). 


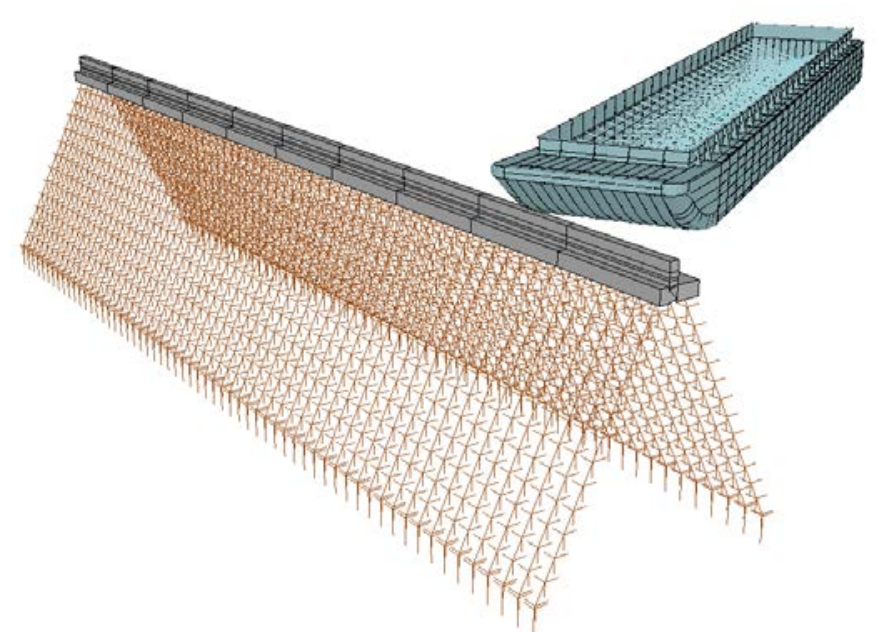

Fig. 11. Rendering of $60^{\circ}$ bow impact scenario with PRO wall. (buoyancy springs attached to barge are omitted for clarity)

\section{Results and discussion}

For every impact condition simulated, the supporting soil was found to have sufficient capacity to withstand the vessel collision and maintain stability of the wall monolith. Barge stress and deformation results from a typical bow impact are shown in Fig. 12. It is noteworthy that even considering the small draft and shallow rake angle, the barge did not ride up and over the wall. Instead, a large indentation formed in the contact area, including some limited tearing of the corner hull plate. Yielding of the steel barge components was limited to an area within $1 \mathrm{~m}$ of the contact region. Similar results were observed for side and stern impacts, but with less damage to the barge than during bow impacts. 


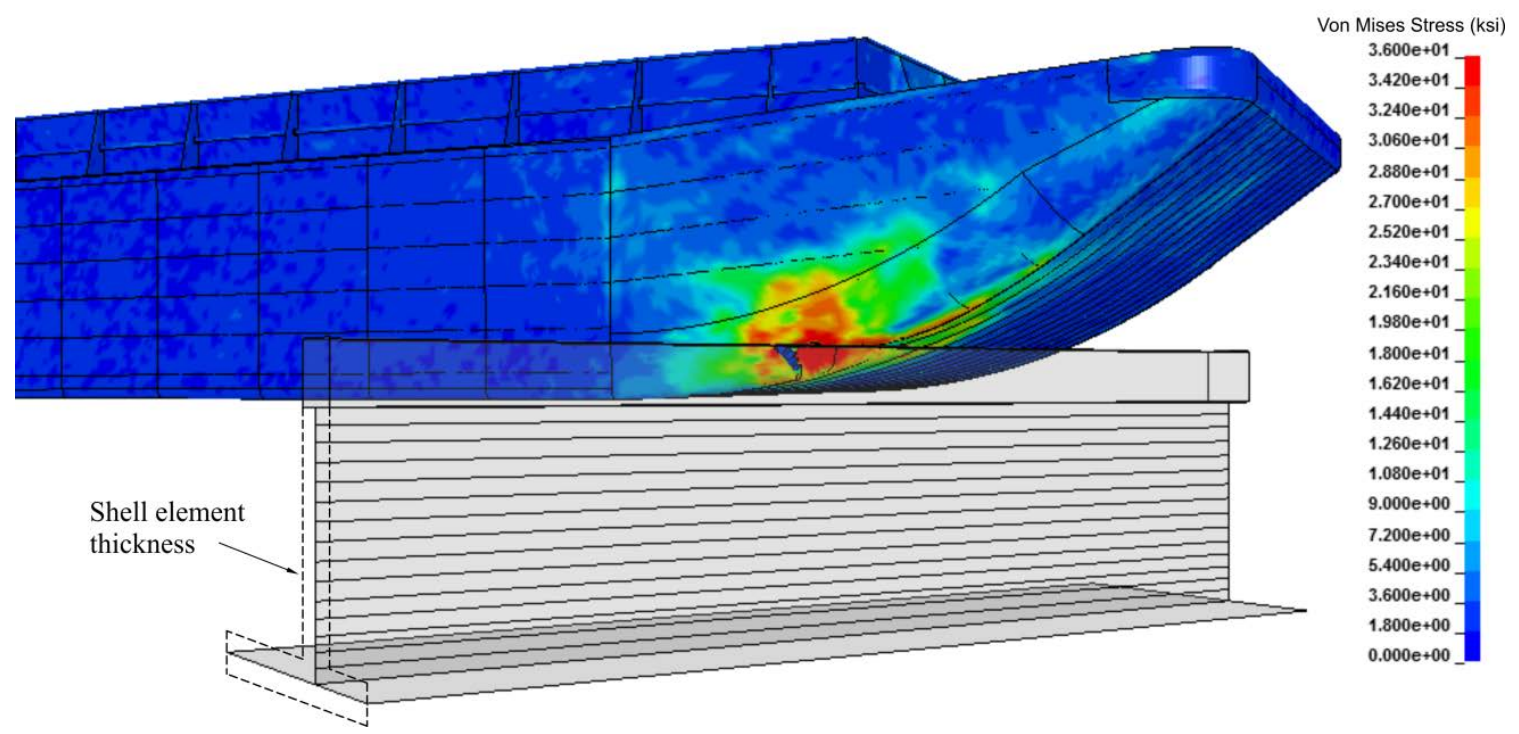

Fig. 12. Bow impact at $60^{\circ}$ into HPO wall. Contour of Von Mises stress (ksi) showing bow corner deformation and tearing of outside hull plates (non-impacted monoliths, piles, buoyancy springs, and finite element mesh lines are omitted for clarity).

\subsection{Impact force time-histories}

Force time-histories for twelve (12) of the sixteen (16) baseline simulations are presented in Fig. 13 (data for $30^{\circ}$ and $45^{\circ}$ impact cases are omitted for clarity in the plots).

During these impact simulations, differing numbers of wall monoliths were engaged, depending on the impact scenario. For example, during broadside impact ( $0^{\circ}$ angle), four monoliths were engaged simultaneously for the HPO wall, and eight for the PRO wall. Thus, for these cases (Figs. 13a-b), a single trace denotes the force per monolith (i.e., total impact force divided by the number of engaged monoliths). During oblique impact scenarios (Figs. 13c-f), initial contact was made with only one monolith, and this initial impact caused the barge to rotate about its center of gravity. Presumably, given sufficient time, barge rotation would result in a subsequent (secondary) impact when the opposite end of the barge collided with the wall. However, a significant portion of the initial barge kinetic energy would be dissipated — through inelastic barge and soil deformations—-during the initial impact such that energy available for the secondary impact would be substantially diminished. Furthermore, viscous damping from the surrounding water would slow the barge 
during rotation and further limit the severity of subsequent impact. Therefore, secondary impacts occurring after barge rotation were not considered as part of this study.

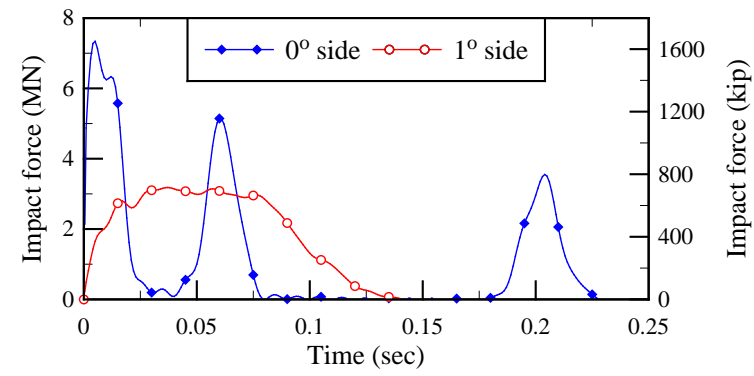

a) HPO wall, side impact

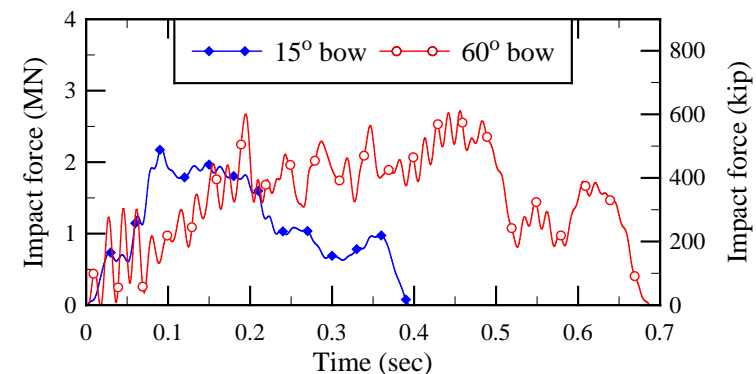

c) HPO wall, bow impact

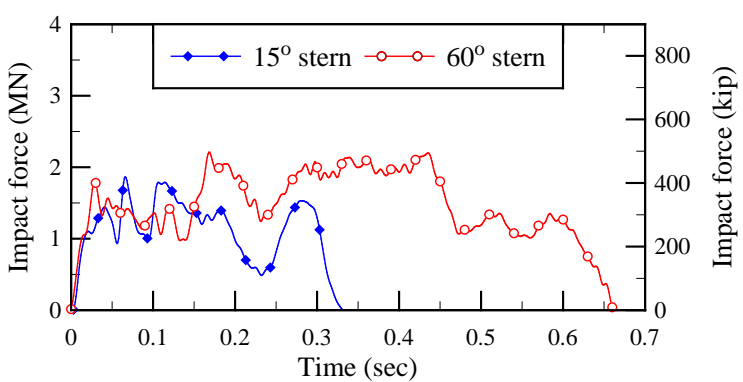

e) HPO wall, stern impact

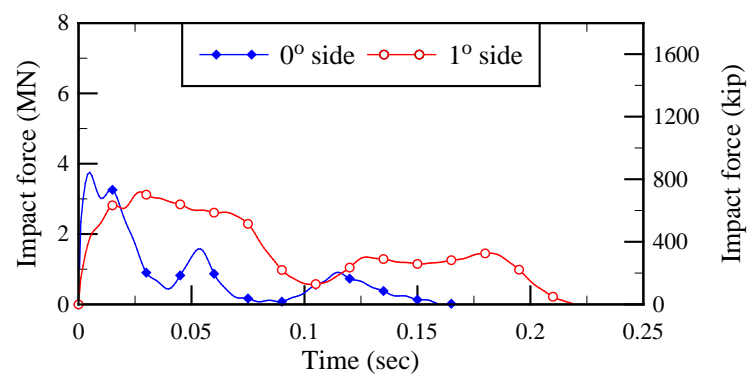

b) PRO wall, side impact

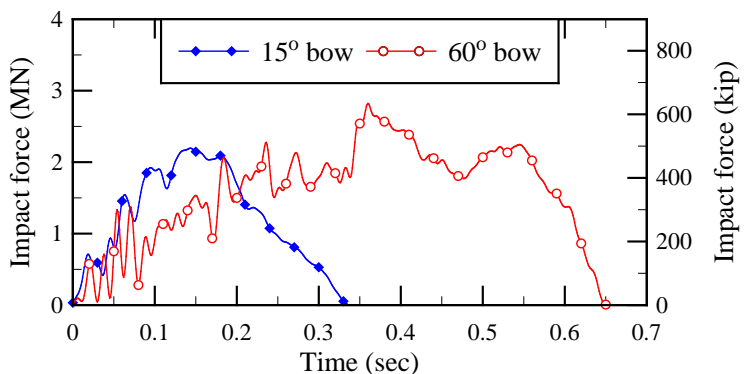

d) PRO wall, bow impact

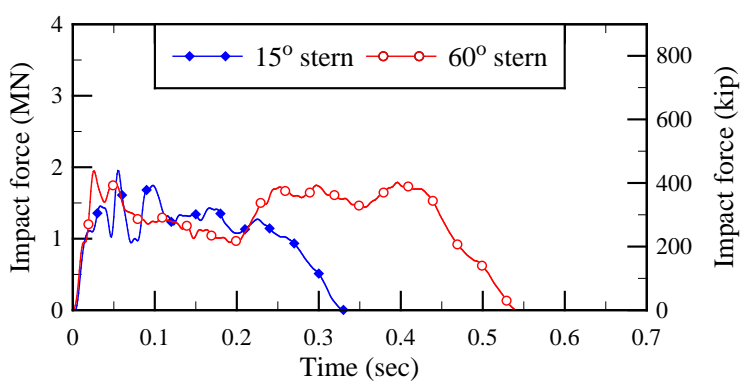

f) PRO wall, stern impact

Fig. 13. Selected impact force-time histories (force component normal to the wall).

Force histories presented in Fig. 13 are considered “raw” data and were minimally filtered using a 100-Hz low-pass filter to eliminate high-frequency noise in the simulation results. Impact forces presented here consist of the force component normal to the wall surface, which corresponds to the primary loading direction of interest for design.

Longitudinal forces are of limited interest because the impacted monolith can rely upon longitudinal capacity provided by abutting monoliths. Further, vertical forces were found to 
be negligible. However, force histories in the vertical and longitudinal directions are documented in [17].

Aside from the $0^{\circ}$ case, impact force magnitudes and durations were similar between the HPO and PRO wall. It is important to note that load durations for the side impact cases $\left(0^{\circ}, 1^{\circ}\right)$ (Fig. 13a-b) were notably shorter than the oblique cases (Fig. 13c-f). For both walls, the $0^{\circ}$ initial load pulse was less than $0.05 \mathrm{sec}$, which was less than one-third the natural periods of the walls $(0.15-0.20 \mathrm{sec})$. Thus, loads associated with broadside impact were approaching the impulsive loading regime. In contrast, For the oblique cases (Fig. 13c-f), significant impact forces were sustained over one or more natural periods of the wall. Forces for stern impact cases rose more rapidly than for corresponding bow impacts, but peak stern force magnitudes were slightly lower than forces associated with bow impact.

\subsection{Maximum impact forces}

As discussed previously, the impact force-histories presented in Fig. 13 are effectively raw data. A 100-Hz low-pass filter was used solely to remove high-frequency noise from each force history. However, significant transient content were still present among the "raw" data. Expectedly, the maximum impact force generated during each simulation occurred at the peak of a short-duration spike in load, sometimes as much as 1 MN (200 kips) higher than the overall trend.

The impact case shown in Fig. 14 exemplifies this sort of short-period oscillation. At approximately $0.21 \mathrm{sec}$, the impact force momentarily rises from less than $1.8 \mathrm{MN}$ (400 kips), to over 2.7 MN (600 kips). However, this spike in impact force was sustained for less than $0.02 \mathrm{sec}$, substantially less than one fundamental period of the HPO wall structure. In this example, the overall maximum force occurred later in time, near $0.5 \mathrm{sec}$, when substantial oscillation was still present. During this span of time, the impact force momentarily reached 2.72 MN (611 kips). 


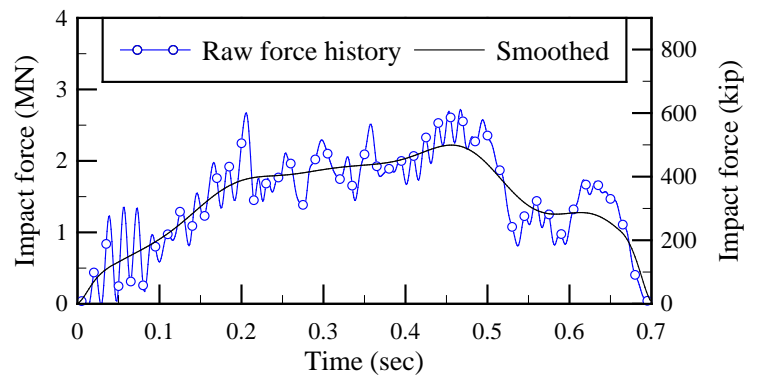

Fig. 14. Force history smoothing algorithm demonstrated for $60^{\circ}$ bow impact with HPO wall.

For the purpose of designing new floodwall structures, the detailed force histories presented in Fig. 13 could be used directly in a dynamic analysis of the wall. This approach is similar to transient seismic analysis, in which the structure being designed is subjected to representative ground acceleration histories that were measured during major earthquakes. However, engineers more often use static load application and analysis techniques to design floodwalls. For impact situations of the type shown in Fig. 14, applying the maximum dynamically-quantified load [2.72 MN (611 kips)] to the wall in a static sense for design purposes would generally be considered overly conservative because the duration of the maximum load is so much shorter than the natural period of the wall (which was determined to be approximately 0.2 sec for both the HPO and PRO walls). Hence, for the types of walls investigated in this study (relatively short walls supported on piles fully embedded in soil), if it is assumed that dynamic amplification phenomena are not significant (see [17] for discussion), then quantifying appropriate static design loads requires more than just the application of a 100-Hz low-pass filter to the raw dynamic impact force data. Therefore, the force-histories computed in this study were additionally post processed using a Gaussian kernel smoothing algorithm to remove short-duration transient spikes deemed to be inconsequential in terms of static wall response. A critical consideration when employing this smoothing technique was appropriate selection of the data range over which the weighted average was computed (i.e., the bandwidth of the Gaussian kernel). Because the fundamental 
natural period of both walls was determined to be approximately $0.2 \mathrm{sec}$, a bandwidth of about one-half of the period $(0.1 \mathrm{sec})$ was selected for use in the kernel smoothing algorithm. As illustrated in Fig. 14, the smoothing algorithm removed short-duration spikes from the force history, leaving only the overall trend of the impact loading event.

By definition, maximum forces obtained from the smoothed force-histories were lower in magnitude than those obtained from raw data. For the case shown in Fig. 14, the raw maximum force was 2.72 MN (611 kips), whereas the maximum force after smoothing was reduced to 2.22 MN (499 kips). A limited-scope investigation indicated that the walls considered in this study were not subject to significant dynamic amplification effects. Consequently, the reduced maximum force (after smoothing) would be more appropriate for use in static analyses conducted to quantify structural demands in the wall or foundation elements. Maximum forces and impact durations computed from each of the 16 baseline simulations are reported in Table 1. Each force value was determined by applying Gaussian kernel smoothing and then computing the force component normal to the surface of the wall.

Table 1. Maximum smoothed impact forces (normal to wall) and impact durations.

\begin{tabular}{|c|c|c|c|c|c|c|c|}
\hline \multirow{2}{*}{$\begin{array}{l}\text { Impact } \\
\text { condition }\end{array}$} & \multirow{2}{*}{$\begin{array}{l}\text { Impact } \\
\text { angle }\end{array}$} & \multicolumn{3}{|l|}{ HPO wall } & \multicolumn{3}{|l|}{ PRO wall } \\
\hline & & $\begin{array}{l}\text { No. of } \\
\text { engaged } \\
\text { monoliths }\end{array}$ & $\begin{array}{l}\text { Maximum } \\
\text { force per } \\
\text { monolith } \\
\text { [MN (kip)] }\end{array}$ & $\begin{array}{l}\text { Impact } \\
\text { duration } \\
\text { (sec) }\end{array}$ & $\begin{array}{l}\text { No. of } \\
\text { engaged } \\
\text { monoliths }\end{array}$ & $\begin{array}{l}\text { Maximum } \\
\text { force per } \\
\text { monolith } \\
{[\mathrm{MN} \text { (kip)] }}\end{array}$ & $\begin{array}{l}\text { Impact } \\
\text { duration } \\
\text { (sec) }\end{array}$ \\
\hline Side & $0^{\circ}$ & 4 & $6.41(1440)$ & 0.040 & 8 & $3.21(722)$ & 0.167 \\
\hline Side & $1^{\circ}$ & 2 & $2.78(625)$ & 0.150 & 2 & $2.71(609)$ & 0.222 \\
\hline Bow & $15^{\circ}$ & 1 & $1.82(410)$ & 0.395 & 1 & $1.94(436)$ & 0.339 \\
\hline Bow & $30^{\circ}$ & 1 & 1.77 (397) & 0.439 & 1 & 1.69 (379) & 0.418 \\
\hline Bow & $45^{\circ}$ & 1 & 1.73 (389) & 0.592 & 1 & 1.63 (367) & 0.597 \\
\hline Bow & $60^{\circ}$ & 1 & 2.22 (499) & 0.709 & 1 & 2.35 (529) & 0.668 \\
\hline Stern & $15^{\circ}$ & 1 & 1.41 (318) & 0.333 & 1 & 1.37 (307) & 0.334 \\
\hline Stern & $60^{\circ}$ & 1 & 1.99 (448) & 0.669 & 1 & $1.60(360)$ & 0.553 \\
\hline
\end{tabular}

For oblique impact scenarios involving the HPO wall (angles $15^{\circ}$ and greater), maximum impact forces varied between 1.3 - 2.2 MN (300 - 500 kips), with an average of 1.8 MN (410 kips). Forces generated during oblique impacts on the PRO wall were similar, varying between 1.3 - 2.4 MN (300 - 530 kips), with an average of $1.8 \mathrm{MN}$ (400 kips). 
Maximum forces generated during side-on $\left(0^{\circ}\right)$, and nearly side-on $\left(1^{\circ}\right)$ collisions were higher than the oblique impact conditions. This difference was especially pronounced in the HPO wall, where the maximum force (per wall monolith) for the $0^{\circ}$ case was almost $300 \%$ larger than the maximum oblique impact force. However, for this same wall, the $1^{\circ}$ collision force [2.8 MN (625 kips)], was only 25\% larger than the most severe oblique force. For the PRO wall, the increase in loads for side-on impact conditions was less severe. Additionally, during a broadside impact $\left(0^{\circ}\right.$ or $\left.1^{\circ}\right)$, a large volume of water must be displaced between the barge and wall, which can slow the barge immediately prior to impact [23]. Because this hydrodynamic cushioning effect reduces the impact speed, the forces predicted by the baseline simulations for $0^{\circ}$ to $1^{\circ}$ —both conducted at a speed of 5 knots normal to the wall—may be overly conservative. Due to the hydrodynamic cushioning effect and the very low probability of a wind-driven barge striking a wall at precisely $0^{\circ}$ (or even $1^{\circ}$ ), the side-on impact conditions were determined to be of reduced importance for wall design [17].

\subsection{Sensitivity to model parameters}

Approximately 30 additional simulations were conducted to assess the sensitivity of barge impact forces to a variety of model parameters: impact velocity (and therefore momentum and energy), position of impact along wall monolith, pile head fixity, soil resistance, and vertical barge position. Each sensitivity study included one or more additional simulations under varied conditions, which were directly compared to the 16 baseline simulations discussed above. Results from the supplemental simulations indicated that maximum forces were not strongly sensitive to most of the model parameters considered. Only the initial impact momentum (or energy) strongly influenced impact force magnitudes. Thus, only results from the sensitivity study for impact momentum are discussed below. Simulation results pertaining to the other sensitivity studies are documented in [17]. 
Additional $60^{\circ}$ bow impact simulations on the HPO wall were conducted to investigate the influence of impact velocity (initial barge momentum) on resulting impact forces. Using an empty barge, the velocity component perpendicular to the wall $\left(\mathrm{V}_{\mathrm{x}}\right)$ was set equal to $1.5,2.1,2.6$, and $3.1 \mathrm{~m} / \mathrm{s}(3,4,5$, and 6 knots), while the longitudinal component $\left(\mathrm{V}_{\mathrm{y}}\right)$ was held constant at $0.6 \mathrm{~m} / \mathrm{s}$ (1 knot). Additionally, one simulation was conducted using a fully-loaded barge (increased mass) with $\mathrm{V}_{\mathrm{x}}=2.1 \mathrm{~m} / \mathrm{s}$ (4 knots). The fully loaded barge had a total weight of 1,490 metric tons (1645 short tons), and a draft of $2.7 \mathrm{~m}(9 \mathrm{ft})$.

Maximum impact forces are summarized and compared to momentum and kinetic energy in Fig. 15. As expected, impact force magnitude and duration increased with increasing initial momentum and kinetic energy. For the cases considered, maximum forces increased with momentum and energy, but only up to a limit. The loaded barge impact case had significantly more initial momentum and energy than any empty barge case. However, this did not result in a larger maximum impact force. Only load duration was affected by increases in momentum and energy. Thus, it appears that with momentum greater than approximately 1,300 kN-sec (300 kip-sec), or energy greater than 1,600 kJ (1,200 kip-ft), impact forces reached a limiting value of approximately $2.5 \mathrm{MN}$ (550 kips). It is worth noting that this outcome-in which impact forces reach a limiting value at higher impact momentums/energies_-is consistent with research findings regarding barge collisions with bridges $[3,4,5,21]$. 


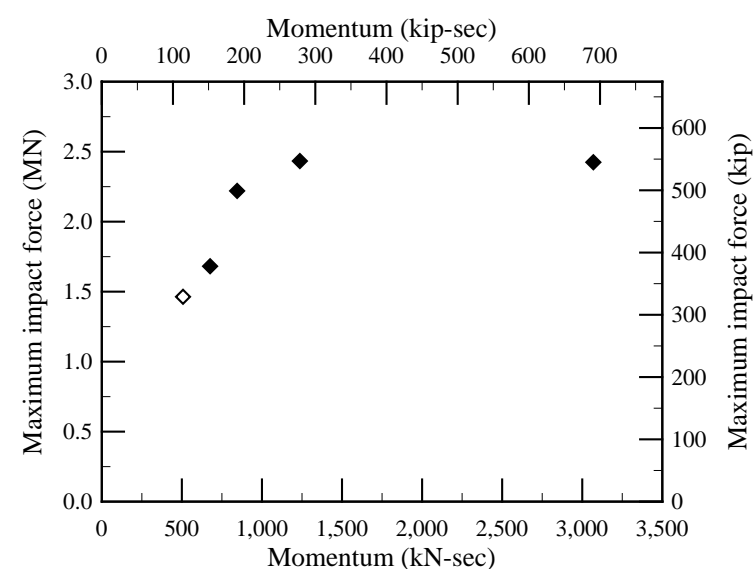

a)

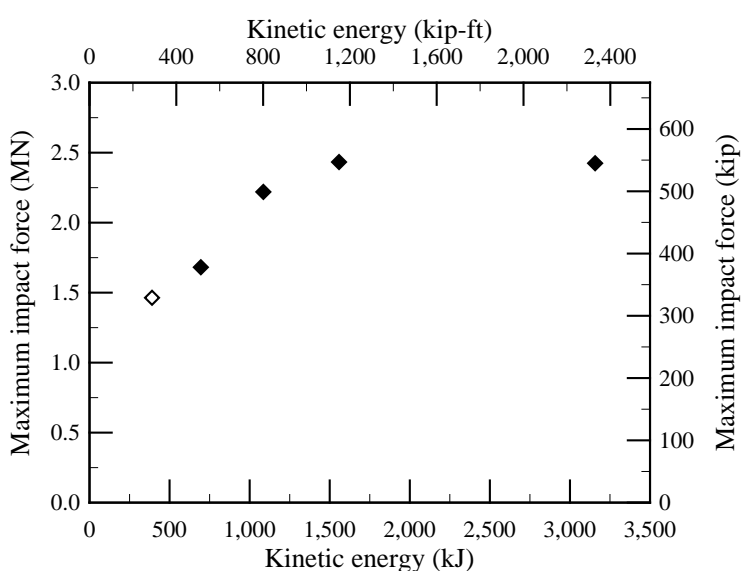

b)

Fig. 15. Sensitivity of maximum impact forces to: a) initial barge momentum, and b) initial kinetic energy.

From a deterministic standpoint, the limiting force level of $2.5 \mathrm{MN}$ (550 kips) is a reasonable candidate for a static design load for hurricane-induced barge impacts on levee walls, provided that dynamic amplification effects in an impacted wall of interest are insignificant. However, it must also be noted that the probability of such severe impact events occurring is statistically small. Because a clear dependence between impact momentum (or energy) and maximum force has been demonstrated, smaller design forces could be justified based on a statistically-based risk assessments. A probabilistic design approach of this type would be consistent with design practice for bridges subject to vessel collision [1,2].

\section{Concluding remarks}

Errant barge vessels pose a serious risk to flood protection structures during hurricane events. As documented in this study, significant impact forces are developed when hurricane winds propel barges into floodwalls. The aim of the current study was to quantify dynamic impact forces associated with specified impact conditions on two common flood-protection wall designs that are in service in the United States. Dynamic force histories were computed using high resolution finite element impact simulations between a jumbo hopper barge and the structures of interest. 
Eight baseline impact conditions were considered for each floodwall structure. Each baseline simulation involved impact at varying angles, at velocities equal to $2.6 \mathrm{~m} / \mathrm{s}$ (5 knots) transverse to the wall and $0.51 \mathrm{~m} / \mathrm{s}$ (1 knot) longitudinally. Force-histories were obtained from each simulation and further processed using a Gaussian kernel smoothing technique.

Maximum forces for perfectly side-on or nearly side-on impact conditions $\left(0^{\circ}\right.$ and $\left.1^{\circ}\right)$, were greater than those produced during oblique impacts $\left(15^{\circ}\right.$ or more). However, several reasons exist for assigning reduced importance to side-on impact forces. Foremost is the duration of the impact event, especially for $0^{\circ}$ cases. For $0^{\circ}$ impact with either wall, the duration of the initial (and dominant) load pulse was less than one-third of the natural period of the structure. Secondly, the probability of a wind-driven barge striking a wall at an angle of $0^{\circ}$ or $1^{\circ}$ is statistically very small. Lastly, due to hydrodynamic cushioning effects, actual barge impact velocities (transverse to the wall) for $0^{\circ}$ or $1^{\circ}$ impacts could be significantly less than the $2.6 \mathrm{~m} / \mathrm{s}$ (5 knots) used in this study.

In addition to baseline simulations, approximately 30 supplemental simulations were conducted to assess the sensitivity of maximum impact loads to various model parameters (e.g., soil resistance, barge impact velocity [and therefore momentum and energy], pile head fixity). Maximum impact forces were generally found to be insensitive to variations in most model parameters. The only parameter that significantly influenced impact forces was initial barge velocity (and therefore momentum and kinetic energy). Impact forces for bow impacts were found to increase along with impact momentum and energy, but ultimately plateau at approximately $2.5 \mathrm{MN}$ (550 kips). It is recommended that appropriate static design loads for hurricane wind-driven barge impacts on floodwalls be determined by combining the deterministically computed impact forces quantified in this study with a probabilistic risk assessment framework that accounts for uncertainties in impact occurrence rates, impact speeds, and impact angles. 


\section{Acknowledgements}

This work was supported under subcontract to Digital Engineering and Imaging Inc., Contract No. 674-01-0198-13, which was under prime contract to the U.S. Army Corps of Engineers, Contract No. W912P8-07-D-0054. Portions of this work were also supported by a National Science Foundation Graduate Research Fellowship. The authors would like to extend thanks to Dr. Patrick Hudson (Moment Engineering) and Dr. Michael McCormick (U.S. Naval Academy) for their contributions to the overall effort of which this work is only part. The authors also thank Mr. Zachary Harper, Mr. Falak Shah, and Mr. Robert Hendrix for their contributions to modeling, simulation, and data processing.

\section{References}

[1] AASHTO. Guide Specification and Commentary for Vessel Collision Design of Highway Bridges. 2nd Ed. Washington D.C.: AASHTO; 2009.

[2] European Committee for Standardization (CEN). Eurocode 1: Actions on Structures Part 1-7: General Actions - Accidental Actions (EN 1991-1-7:2007-02). Brussels: CEN; 2007.

[3] Yuan P, Harik IE, Davidson MT. Multi-Barge Flotilla Impact Forces on Bridges, Research report KTC-08-13/SPR261-03-2F. Lexington: Kentucky Transportation Center, University of Kentucky; 2008.

[4] Consolazio GR, Davidson MT, Cowan DR. Barge Bow Force-Deformation Relationships for Barge-Bridge Collision Analysis. Transport Res Rec 2009; 2131:3-14.

[5] Getter DJ, Consolazio GR. Barge Bow Force-Deformation Relationships for Bridge Design with Probabilistic Consideration of Oblique Impact Scenarios. Transport Res Rec 2011; 2251:3-15. 
[6] Consolazio GR, Cowan DR. Numerically Efficient Dynamic Analysis of Barge Collisions with Bridge Piers. J Struct Eng 2005;131(8):1256-66.

[7] Getter DJ, Consolazio GR, Davidson MT. An Equivalent Static Analysis Method for Barge Impact-Resistant Bridge Design. J Bridge Eng 2011;16(6):718-27.

[8] Patev RC, Barker BC, Koestler LV. Prototype Barge Impact Experiments, Allegheny Lock and Dam 2, Pittsburgh, Pennsylvania. Washington DC: U.S. Army Corps of Engineers (USACE); 2003.

[9] Patev RC, Barker BC, Koestler LV. Full-Scale Barge Impact Experiments, Robert C. Byrd Lock and Dam, Gallipolis Ferry, West Virginia. Washington DC: U.S. Army Corps of Engineers (USACE); 2003.

[10] U.S. Army Corps of Engineers (USACE). ETL 1110-2-563: Engineering and Design, Barge Impact Analysis for Rigid Walls. Washington DC: USACE; 2004.

[11] Livermore Software Technology Corporation (LSTC). LS-DYNA Keyword User’s Manual Vol. I; Livermore: LSTC; 2014.

[12] Livermore Software Technology Corporation (LSTC). LS-DYNA Keyword User’s Manual Vol. II Material Models; Livermore: LSTC; 2014.

[13] Livermore Software Technology Corporation (LSTC). LS-DYNA Theory Manual; Livermore: LSTC; 2014.

[14] Consolazio, G.R., Walters, R.A., Harper, Z.S., Development of Finite Element Models for Studying Multi-Barge Flotilla Impacts. Structures Research Report No. 2012/87754. Gainesville: University of Florida; 2012. 
[15] Consolazio, G.R., Walters, R.A., Development of Multi-Barge Flotilla Finite Element Models For Use in Probabilistic Barge Impact Analysis Of Flexible Walls. Structures Research Report No. 2012/94753. Gainesville: University of Florida; 2012.

[16] Kantrales, G.C., Consolazio, G.R., Wagner, D., Fallaha, S. Experimental and Analytical Study of High-Level Barge Deformation for Barge-Bridge Collision Design. J Bridge Eng. (In press, 2015).

[17] Consolazio GR, Davidson MT, Getter DJ. Development and Support of Dynamic Numerical Modeling of Aberrant Rake Barges Impacting Hurricane Protection Structures Subjected to Forces from a Hurricane Environment. Structures Research Report No. 2010/83710. Gainesville: University of Florida; 2010.

[18] Matlock H. Correlations for Design of Laterally Loaded Piles in Soft Clay. In: 2nd Annual Offshore Technology Conference. Houston; 1970;OTC 1204.

[19] Reese LC, Cox WR, Koop FD. Analysis of Laterally Loaded Piles in Sand. In: 5th Annual Offshore Technology Conference. Houston; 1974;OTC 2080.

[20] McVay MC, O'Brien M, Townsend FC, Bloomquist DG, Caliendo JA. Numerical Analysis of Vertically Loaded Pile Groups. In: ASCE Foundation Engineering Congress. Northwestern University, Illinois; 1989;675-90.

[21] Consolazio GR, Cook RA, McVay MC, Cowan DR, Biggs AE, Bui L. (2006). Barge Impact Testing of the St. George Island Causeway Bridge. Structures Research Report No. 2006/26868. Gainesville: University of Florida; 2006. 
[22] Davidson, MT, Consolazio GR, Getter, DJ (2010). Dynamic Amplification of Pier Column Internal Forces Due to Barge-Bridge Collision. Transport Res Rec 2010;2172:11-22.

[23] Patev RC, Consolazio GR, Hudson P, McCormick M, Marr B, Walker CJ, Hokens K. Aberrant Barge Impact Loads on Hurricane and Storm Damage Risk Reduction System (HSDRRS) Floodwalls. Washington DC: U.S. Army Corps of Engineers (USACE). 